\title{
Management of the Quality of Corrosion Protection of Structural Steel Based on Corrosion Risk Level
}

\author{
Volodymyr Korolov $^{1}$, Yury Filatov ${ }^{2}$, Natalya Magunova ${ }^{3}$ and Petro Korolov ${ }^{2}$ \\ 1. Priazovsky State Technical University, Mariupol 87500, Ukraine \\ 2. Donetsksteel, Iron and Steel Private Stock Corporation, Donetsk 83062, Ukraine \\ 3. V. Shimanovsky Ukrainian Institute of Steel Structures, LTD, Donbass Centre of Engineering Safety, Makeevka 86123, Ukraine
}

Received: September 07, 2013 / Accepted: October 03, 2013 / Published: November 25, 2013.

\begin{abstract}
The paper deals with the theoretical and practical aspects of improving regulatory and technical framework for assuring the quality and safety of metal structures and their protective coatings under the exposure of corrosive environment. Methodological approach has been developed to managing technological safety, assessing the risks of corrosion failures, and extension of an industrial facility's life based on company standards taking into account the requirements for safe operation of buildings and installations. Basic provisions of the method of limit states design have been analyzed to determine: design characteristics of corrosion impacts, computational models and design cases for affirming compliance of corrosion resistance, and durability and maintainability of structures and their protective coatings. Presented are practical examples of justifying the choice of means of primary and secondary protection, taking into account classification of the established levels of facility corrosion hazard. On the basis of limit state design principles, logistical control- and decision-making system is generated for reliability assurance of steel structures and protective coatings. Assessment criteria are specified for the risks with the use of the materials and technologies of primary and secondary corrosion protection.
\end{abstract}

Key words: Steel structures, corrosion protection, limit state calculation, corrosion resistance, durability, maintainability, technological safety, corrosion risk level.

\section{Introduction}

Under the present-day conditions of the common use of metals in the construction industry and improvement of architectural expressiveness of constructed facilities, means and methods of corrosion protection should support the long-term service life of structures. It should be noted to date there are no effective mechanisms that would satisfy the economic approach to increasing the efficiency of the measures of corrosion protection when assuring reliability and technological safety of metal structures.

Increase of the steel corrosion resistance, rational choice of construction approaches, increase of material

Corresponding author: Volodymyr Korolov, professor, research fields: specifics of formulating safety critical function for steel structures in corrosive environments. E-mail: center_sts@ukr.net. concentration in cross-sections, reduction of the influence of internal factors on initiation of local, pitting, contact, and crevice corrosion, corrosion cracking and corrosion fatigue characterize the efficiency of primary protection measures. Secondary protection provides a restriction or elimination of environmental impacts on the structure, increases structural durability with the use of corrosion protection coatings. Justification of the means of corrosion protection during the facility service life reflects the conditions of the assessment of limit states and requirements of structural reliability assurance [1-4].

The basis for forming the requirements to technological safety is comprised of the theory of technogenic and natural disasters, aspects of legal and economic risk management, and methods and systems of diagnostics, monitoring, and engineering protection. 
With this, technogenic safety determines the degree of protection of human beings, facilities and environment from built and operated complex technical systems of civil and industrial designation. The subject of activity in the field of industrial safety is the degree of human protection from hazardous industrial factors. Therefore, on the national level, technological safety determines the degree of protection of human beings, society, facilities and environment from the threats due to unreasonable creation or not creation of technical systems, technological processes and materials.

Formation of the requirements for safe operation of buildings and installations requires assurance of the quality of corrosion protection and assessment of risks of a corrosive failure. This paper is aimed to analyze the possibilities for prescriptive technical regulation, implementation of management measures for diagnostics and corrosion monitoring to ensure safety and corrosion protection of industrial facilities. Reducing the corrosion risk level of industrial facilities comprises coordination, regulatory, control, investment and technological components of the safe operation of buildings and installations under aggressive, environmental, and industrial impacts [5-7].

\section{Principles of Quality Management}

The methodology of ISO 9001:2000 standard series includes eight principles of quality management, which promote achievement of purposes for a developed system and organizational management structure in the course of designing, manufacturing and use of metal structures. Development of the means and methods of corrosion protection for maintaining given indices of reliability and safety should provide technical regulation based on customer requirements of constructive and technological measures of primary and secondary protection upon a change of the design case that sets operational characteristics of the facility. Management policy specifies the purposes of quality management based on the parameters of corrosion resistance and durability formulated in the technical assignment for design. Design models of transformation of the requirements of reliability and safety into characteristics of operational quality of structures determine the methods of quality monitoring, diagnostics of corrosion state, and advisability for involvement of specialized organizations and experts with quality attesting. Thus, the quality assurances presented in the design and manufacturing specifications for service life are implemented on the basis of a process approach, which reflects the system of structural maintenance service and repair during the specified service life. The system approach to management implies identification and formalized description of the stress-strain state of a structure on the basis of relationships in the corrosion system "Loading-Structure-Environment". The developed procedure for corrosion state monitoring allows assessing the parameters of regulating structural service life for implementation of the policy of continuous improvement aimed at improving the measures of primary and secondary protection. The benefits of the registration method of assessing the parameters of structural steel repairability upon the actual state allow formulating an approach to decision-making to assure technological safety of structures in corrosive environments.

It is possible to conclude that the proposed organizational structure of mutually beneficial cooperation with suppliers based on the principles of corrosion protection quality management is a basis for justifying guaranteed qualities of corrosion resistance and durability in the metal structure manufacturing.

The basis of the logistical approach and methods of risk analysis is comprised of information databases and simulation models, including analytical, technological and marketing tasks. Justification of the decision-making linked with the rational choice of corrosion protection measures depends on the degree of completeness of information (Fig. 1). 

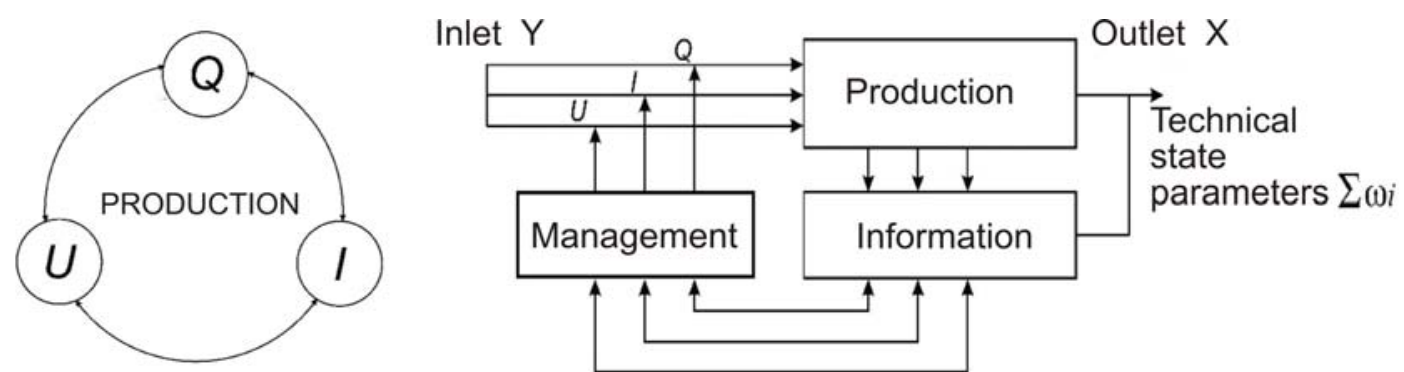

Fig. 1 Diagram of the process approach and structural and organizational model of material (Q), information (I) and management $(\mathrm{U})$ components of risk-analysis of the corrosion protection management system.

According to the developed approach, assessment of the quality of structures is based on the compound of indices of corrosion resistance, durability and repairability, which determine standard requirements for safety and serviceability of buildings and installations.

The choice of methods of corrosion protection of structural steel is affected by operating conditions, degree of corrosion impact, and structural features. Criterion for solving the logistical problem of justifying the means and methods of corrosion protection is the minimum cost of maintaining the quality and safety of the facility for its specified service life.

Decision-making procedure involves various levels and models of rational choice, which determine the cost-effectiveness of measures for reducing the level of risk (Fig. 2).

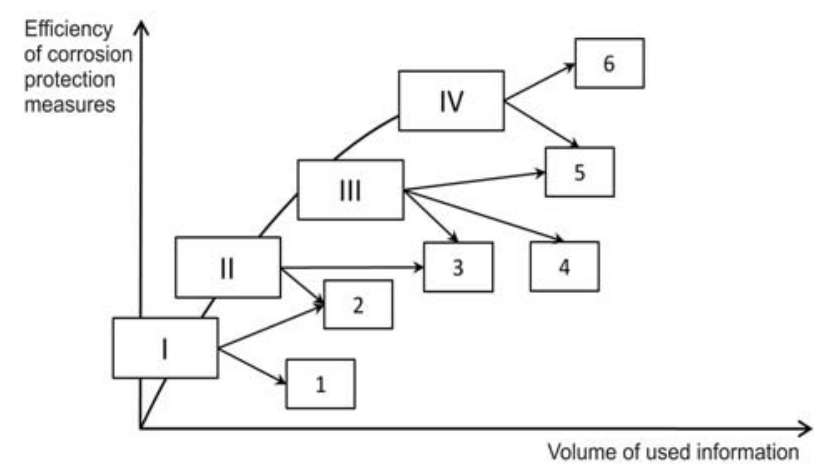

Fig. 2 Influence of the level of decision-making and model of rational choice on reduction of corrosion protection costs. Symbols. Decision-making levels: I is affective; II is traditional; III is value-rational; IV is target oriented. Rational choice models: (1) satisfaction; (2) costs; (3) reliability; (4) programming; (5) training; (6) evolution.

\section{Indices of Reliability of Primary and Secondary Corrosion Protection Based on the Requirements of Limit States Methodology}

In the field of construction, technological safety is linked with regulation of approaches to preventing emergency situations on the basis of methods of program-oriented management of structural reliability of buildings and installations. The concept of preventing progressive ageing of fixed assets is based on the process-based approach to problems of ensuring technological safety of constructed facilities. Technological safety is an important structural component of enterprise safety, which characterizes a With this approach the concept of corrosion risk hazard involves a certain condition or situation (threat) at which the probability of loss increases due to the fact that the given corrosion state or deviation from normal operation are a potential cause (threat) of hazard or something that may affect the magnitude of loss.

The sequence of stages of the methodological approach to managing means and methods of corrosion protection of structural steel based on the requirements of technological safety is shown in Fig. 3. Requirements for primary and secondary protection are set upon agreement with the customer of a standard operation model for which a nomenclature of reliability indices is developed. Design preparation for fabrication is linked with the analysis of opportunities of primary protection at "KM" stage (design drawings of metal structures) and requirements for corrosion resistance in KMD working drawings (shop drawings). 


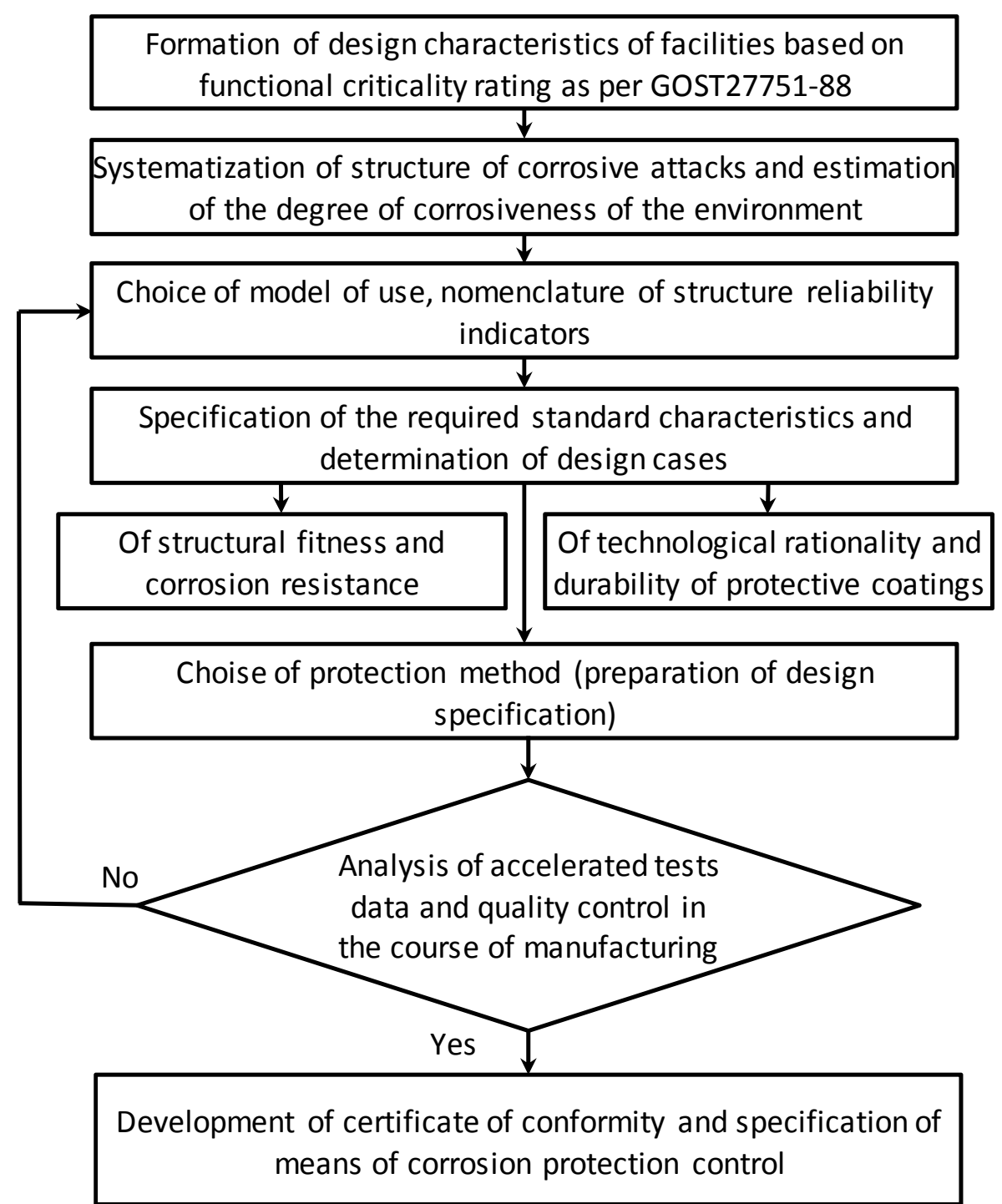

Fig. 3 Sequence of design and technological development of the measures of primary and secondary protection in manufacturing structures with guaranteed durability.

When choosing means of secondary protection, parameters of technological rationality are considered, linked with the conditions of manufacturing, installation and use. To substantiate corrosion resistance, durability, and reparability requirements, means of primary and secondary protection are chosen based on the results of simulation of the design cases for the specified service life of the structure.

The structural steel availability factor $\left(K_{g}\right)$ is a complex index of repairability characterizing parameters of structural and technological measures of primary and secondary protection:

$$
K_{g}=\frac{T_{k \gamma}+T_{z \gamma}}{T_{k \gamma}+n T_{z \gamma}}
$$

where, $T_{k \gamma}$ is service life (year) of steel structures according to corrosion resistance index (primary protection); $T_{z \gamma}$ is design service life (year) of protective coatings with confidential probability of $\mathrm{g}=$ 0.95 based on results of accelerated tests; $n$ is number of repair cycles for renewal of corrosion protection at the facility specified service life.

Structural steel calculations for corrosion resistance, durability and repairability are linked with the consideration of quality indices of the measures of 
primary and secondary protection based on the attributes of first and second limit states (Fig. 4).

Methodological basis for determining durability of steel structures and their protective coatings is an analythical-experimental estimate of reliability factors of primary $\left(\gamma_{z k}\right)$ and secondary $\left(\gamma_{z n}\right)$ protection, compliant with the given constraints based on the limit states . Corrosion protection reliability factors $\left(\gamma_{z \kappa}, \gamma_{z n}\right)$ specify the permissible deviations of strength, deformation and performance properties of structural members determined for the standard model of facility operations and specified service life ( $T_{n \gamma}$, year). Requirements to durability indices for primary and secondary protection are set with account for the specified service life $T_{n \gamma}$ of steel structures and degree of corrosiveness of the environment.

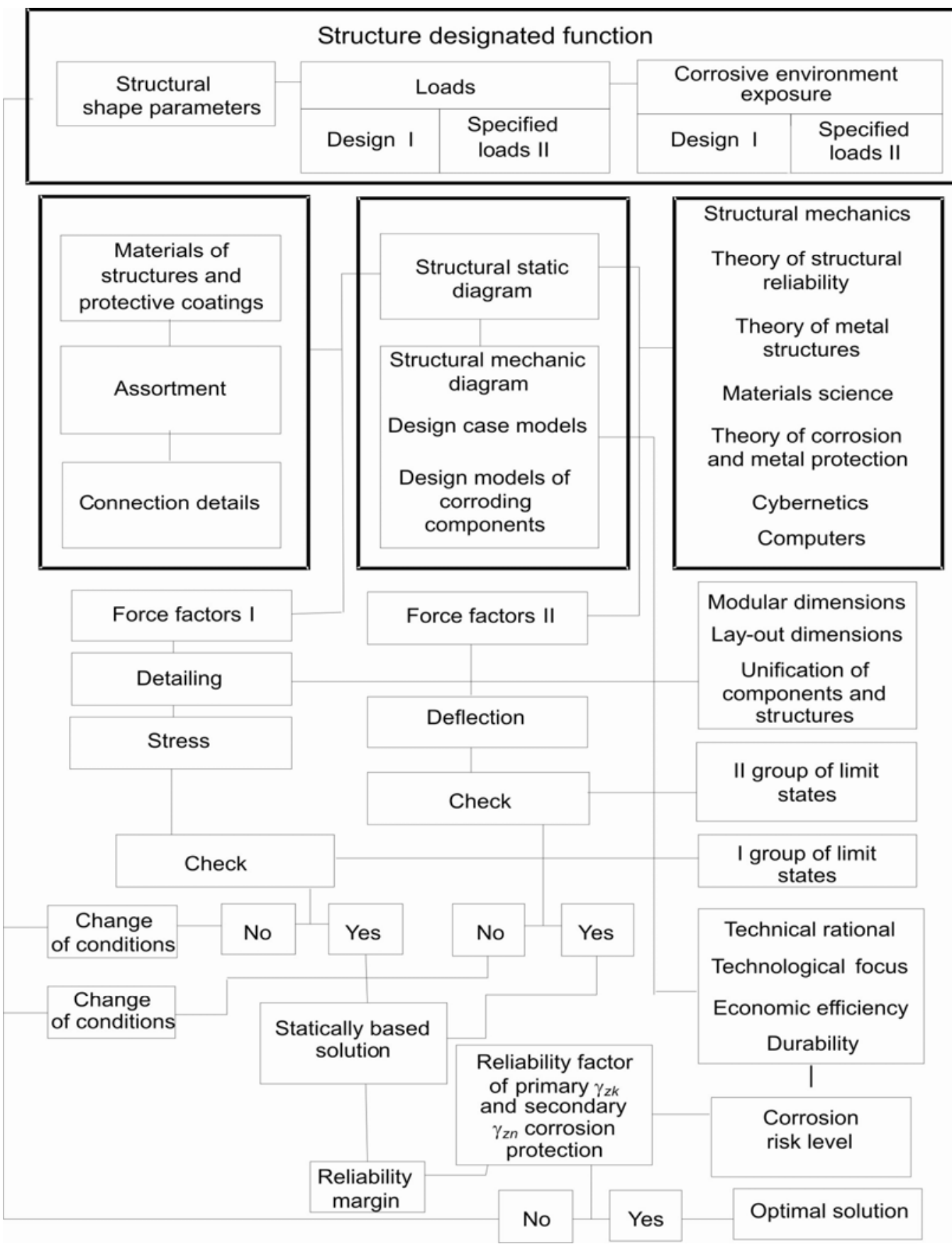

Fig. 4 System of choice of indices of primary and secondary protection of structural steel based on corrosion risk. 


\section{Estimation of Availability Factor of Steel Structures in the Course of Accelerated Tests and Based on Monitoring of Corrosion State}

It is suggested that a comparative analysis of the durability of corrosion protection of structures and installations be carried out as per the developed methodology, taking into account availability factor of steel structures $\left(K_{g}\right)$. The task of determining availability factor under corrosive exposure $(A, \mathrm{~g} / \mathrm{sq} \cdot \mathrm{m}$ per year) is formulated as a structural steel limit state calculation for corrosion resistance and durability based on the results of accelerated corrosion tests of protective coatings.

The accelerated corrosion tests are aimed at the design calculation of the parameter $T_{z \gamma}$ for comparative determination of the conformity of the various systems of protective coatings to the design cases based on corrosion resistance and durability indices.

The essence of the accelerated test method per GOST 9.401" ESZKS, "Paint-and-lacquer coating, the general requirements and methods of accelerated tests for resistance to exposure to climatic factors" is the impact on samples with protective coatings of artificial conditions simulating the impact of corrosion-active components of the environment. The sequence of conducting the test is regulated with the requirements of ISO Standard 12944-6. Tests of physical-mechanical and protective properties were carried out on standard samples. The estimation of properties of protective coatings was made according to the requirements of GOST 9.407.

Expert estimate of the overall index of coating protective properties $\left(A_{z}\right)$ was carried out using the correlation:

$$
A_{z}=\sum_{i=1}^{i=N} B_{i} X_{i}
$$

where, $B_{i}$ is factor of ponder ability of failure mode; $X_{i}$ is relative estimation of $i$-type failure; $i$ is number of failure modes.
The reaction of the resistance to the surface failure $[F(N), \mathrm{g} / \mathrm{sq} \cdot \mathrm{m}]$ is described on the basis of an analytical approach considering interaction of the parameters of the structural form $(j)$ and factors of corrosive exposure (i):

$$
\begin{gathered}
F(N)=A_{i}+A_{j}+A_{i, j}+A_{i, j-1} \\
A_{i, j}=a_{0} \sum_{i=0}^{i=N} \sum_{j=0}^{j=L} a_{i, j} / T_{k}
\end{gathered}
$$

where, $A_{i(j)}$ is system variable of corrosion losses, $\mathrm{g} / \mathrm{sq} \cdot \mathrm{m}$ per year; $a_{i(j)}$ is weight characteristic of the structural form parameters $(i, j) ; a_{0}$ is corrosion losses of C235 steel $(\mathrm{g} / \mathrm{sq} \cdot \mathrm{m})$ under accelerated corrosion tests in $720 \mathrm{~h} ; T_{k}$ is time interval corresponding to the settled corrosion losses (per year).

Service life of the protective coating system (PCS) was specified according to the experimental data of the accelerated corrosion tests with the formula:

$$
T_{z}=\Delta P(N) / A_{n}
$$

where, $P(N)$ is corrosion losses of unprotected steel corresponding to the number of cycles of accelerated tests $\mathrm{N}$ prior to the specified characteristic of failure, $\mathrm{g} / \mathrm{sq} \cdot \mathrm{m} ; A_{n}$ is characteristic value of annual corrosion losses $\mathrm{g} / \mathrm{sq} \cdot \mathrm{m}$.

Thus, based on the experimental data of accelerated corrosion tests, statistical estimate of reliability factor $\gamma_{z n}$ is carried out and acceptability constant of the protective coating system is specified for determining guaranteed durability and repairability of structures. Results of control of the quality indices are used for making aspecification of structural members and materials based on corrosion resistance, durability and reparability (Table 1$)$.

\section{Monitoring of Indices of Corrosion Protection Quality in Service}

To estimate the properties of corrosion protection in service, the procedure of audit of structural corrosion state with operational quality index $F_{e}$, determined by the method of G. Taguti, was used. 
Quality index $F_{e}$ is a relative characteristic of efficiency of the measures of primary and secondary protection for determining the risk level based on technological safety $\left(R_{i}\right)$, with account for the actual corrosion impacts of facility operations. To determine corrosion resistance indices, bench tests were conducted on samples of VCt3pc5 and 09G2C steels placed in the conditions of the operating facility.
These tests demonstrated conformity of the design characteristics of the corrosion state of the structures and their protective coatings to the character and intensity of the impacts of the operating environment.

The program of monitoring the corrosion state of spanning steel structures of conveyor galleries includes the requirements of DBN V.1.2-5 for scientific and technical support of facility service life (Fig. 5).

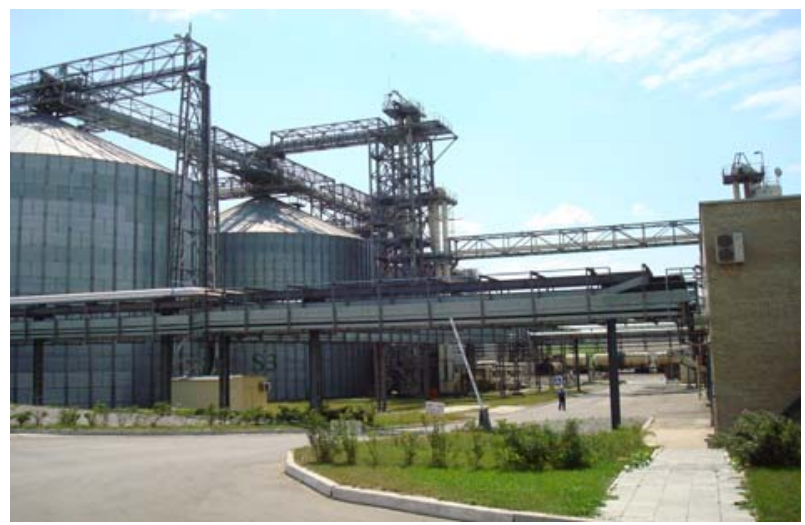

(a)

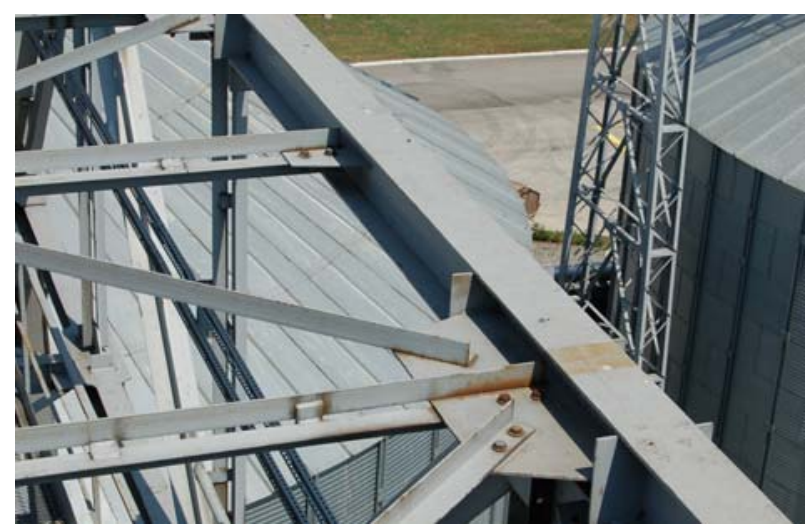

(b)

Fig. 5 Corrosion state of bearing steel structures. (a) appearance of the facility's conveyor galleries and (b) corrosion state of the structures and their protective coatings after 8 years of use.

Table 1 Specification of quality indices based on results of control of primary and secondary protection means in the course of fabrication.

\begin{tabular}{|c|c|c|c|c|c|c|c|}
\hline Item & $\begin{array}{l}\text { Indication of members of } \\
\text { conveyor span, structure } \\
\text { materials and protective coats } \\
\text { system }\end{array}$ & $\begin{array}{l}\text { Indication according } \\
\text { to snip } \\
2.03 .11-85^{*} \\
\text { Surface preparation }\end{array}$ & $\begin{array}{l}\text { Index } \\
B_{o z}\end{array}$ & $\begin{array}{l}\text { Characteristic of } \\
\text { using environment } \\
\text { corrosiveness } A_{n} \text {, } \\
\mathrm{g} / \mathrm{sq} \cdot \mathrm{m} \text { per year) }\end{array}$ & $\begin{array}{l}\text { Service life of } \\
\text { structures, } \\
\text { covering } T_{n \gamma} / T_{z \gamma} \\
\text { year }\end{array}$ & $\begin{array}{l}\text { Availabilit } \\
\text { y factor, } \\
K_{g}\end{array}$ & $\begin{array}{l}\text { Reliability } \\
\text { factor, } \\
\gamma_{z n} / \gamma_{z k}\end{array}$ \\
\hline 1 & $\begin{array}{l}\text { Grade F1, I } 30 \text { VSt3sp5, TsBAS } \\
\text { №1 }\end{array}$ & \multirow{4}{*}{$\frac{\text { Ia-2 (80) }}{\text { PSt2 }}$} & \multirow{4}{*}{4.3} & \multirow{4}{*}{850} & \multirow{4}{*}{$50 / 15.5$} & 0.65 & $0.93 / 0.95$ \\
\hline 2 & $\begin{array}{l}\text { Grade F1, I } 24 \text { VSt3sp5, TsBAS } \\
\text { №1 }\end{array}$ & & & & & 0.6 & $0.93 / 0.91$ \\
\hline 3 & Grade B1, I 20 VSt3sp5 & & & & & 0.55 & $0.93 / 0.88$ \\
\hline 4 & $\begin{array}{l}\text { Grade BZ, }-220 \times 10,-220 \times 8, \\
\text { 09G2S, TsVAS №1 }\end{array}$ & & & & & 0.55 & $0.93 / 0.90$ \\
\hline
\end{tabular}

Table 2 Classification features of corrosion risk level of structures, buildings and installations.

\begin{tabular}{|c|c|c|c|c|c|}
\hline \multirow{2}{*}{ Degree of exposure corrosiveness $K, \mathrm{~mm}$ per year } & \multicolumn{5}{|c|}{ Range estimates of corrosion protection availability factor, $K_{g}$} \\
\hline & $0<K_{g} \leq 0.1$ & $0.1<K_{g} \leq 0.3$ & $0.3<K_{g} \leq 0.5$ & $0.5<K_{g} \leq 0.7$ & $0.7<K_{g} \leq 1.0$ \\
\hline $\begin{array}{l}\text { Weak-level corrosive environment, } \\
0.01<K \leq 0.05\end{array}$ & KI & $*$ & $*$ & $*$ & $*$ \\
\hline $\begin{array}{l}\text { Low-level corrosive environment, } \\
0.05<K \leq 0.08\end{array}$ & KII & KI & $*$ & $*$ & $*$ \\
\hline $\begin{array}{l}\text { Average-level corrosive environment, } \\
0.08<K \leq 0.20\end{array}$ & KIII & KII & KI & $*$ & $*$ \\
\hline $\begin{array}{l}\text { High-level corrosive environment, } \\
0.20<K \leq 0.50\end{array}$ & KIV & KIII & KII & KI & $*$ \\
\hline $\begin{array}{l}\text { Strong-level corrosive environment, } \\
K>0.50\end{array}$ & KV & KIV & KIII & KII & KI \\
\hline
\end{tabular}

* designates that for the specified interval values of $\left(K, K_{g}\right)$ features the level of corrosion risk is not standardized. 
The established methodical approach to assessing the efficiency of primary and secondary protection measures is used for classification of corrosion risk levels KI-KV (Table 2).

\section{Conclusions}

The use of corrosion risk criterion makes it possible to specify the requirements to choosing measures of primary and secondary protection. As well, it establishes control values for substantiating the system of facility maintenance and technical support, depending on intensity of corrosion impacts and availability factor of corrosion protection. Thus, conditions are created for technical regulation of the requirements for technological safety in all stages of structural life cycle, including the formation of a system of measures of emergency prevention for the facilities with high corrosion risks.

\section{References}

[1] R.N. Parking, Life Prediction of Corrodible Structure,
NACE, Houston, 1994, pp. 14-21.

[2] E.V. Gorokhov, V.P. Korolyov, Durability of Steel Structures under Reconstruction, Rotterdam, Brookfield, 1999, pp. 254-261.

[3] Manual of Steel Construction, American Institute of Steel Construction, Load and Resistance, Factor Design, 3rd ed., 2001, pp. 2-48.

[4] J. Tidblad, K. Kreislova, New Developments in the Classification of Corrosivity of Atmospheres, Corrosion News, 2012, pp. 10-11.

[5] G.C. Moran, P. Labine, Corrosion Monitoring in Industrial Plants Using Nondestructive Testing and Electrochemical Methods, ASTM, Philadelphia, 1986, pp. 197-219.

[6] M.G.S. Ferreira, C.A. Melendres, Electrochemical and Optical Techniques for the Study and Monitoring of Metallic Corrosion, Kluwer Academic Publishers, Dordrecht-Boston-London 1991 (Materials of NATO Conference, NATO ASI E 203, Portugal, 1989).

[7] A.V. Shimanovsky, V.N.Gordeev, V.P. Korolov, A.I. Ogloblya, I.R.Ruhovich, Y.V. Filatov, Technical Diagnostics and Prevention of Emergency Situations for Structures of Buildings and Installations, Kiev, ed., "Steel", 2008, pp. 72-88. 